remission.. Further studies are needed to establish the impact of US on therapeutic decision-making in JIA.

Disclosure of Interest: None declared

DOI: 10.1136/annrheumdis-2018-eular.4871

\section{THU0564 $\quad$ EFFICIENCY AND SAFETY EVALUATION OF BIOSIMILAR INFLIXIMAB FOR TREATMENT OF PAEDIATRIC NON-INFECTIOUS UVEITIS IN SINGLE CENTRE}

B. Sozeri ${ }^{1}$, E. Kardes ${ }^{2}$, L.G. Bolac ${ }^{1}$, B.I. Sezgin Akçay ${ }^{2} .{ }^{1}$ Pediatric Rheumatology; ${ }^{2}$ Ophthalmology Clinic, University of Health Sciences, Istanbul, Umraniye Training and Research Hospital,, Istanbul, Turkey

Background: Biosimilar infliximab (Remsima) has been introduced in our country, together with other European countries in 2014. Information regarding the use in child age group is limited but it is reported that its therapeutic efficiency and safety is similar to the reference molecule regarding the paediatric Chron disease Objectives: In this study, our aim was to reporte the efficiency and safety of $\mathrm{BI}$ used for children with non-infectious uveitis

Methods: In this study, there were 13 subjects ( 9 boys, and 4 girls) diagnosed with non-infectious uveitis.

$\mathrm{BI}$ (Remsima9 treatment had been given in $5 \mathrm{mg} / \mathrm{kg}$ in 0.,2.,4 th week and then every 8 th week. Ophthalmic assessment of disease activity and ocular complications were measured throughout the trial with the use of slit-lamp biomicroscopy for uveitis activity, according to the SUN criteria. The Drug exposure has been evaluated by calculated of patient year (HY), adverse event ( $A E)$ was assessed using the CTCAE criteria. The median values due to the small number of patients are considered

Results: The patients who were include the study, 5 had diagnosed extended oligo JIA, 2 with enthesitis-related arthritis (ERA), 2 with persistent oligo JIA, 2 with pars planitis and one of them Behcet's disease. At the time of evaluation, the median age was 10 years, ${ }^{3-13}$ age at diagnosis of their disease 8 years, ${ }^{1-13}$ respectively. The median age of uveitis diagnosis was 8 years. The median disease duration before $\mathrm{BI}$ was 10 months. All of the patients had methotrexate therapy with $\mathrm{BI}$ and $\mathrm{BI}$ before.

Only one patient used a different biological agent prior to $\mathrm{BI}$, and revealed they were determined that considered unresponsive.

Other patients $(n=12)$ had biosimilar infliximab as first biologic drug due to the activation of disease after using the drug methotrexate.

After therapy of $\mathrm{BI}$, in all of the patients, joint and eye symptoms were improvement.

The systemic steroid therapy was cut down in the first month in all patients, 2 of them continue prophylactic topical steroids.

The median duration of $\mathrm{BI}$ therapy was 10 months. There was one case of anaphylaxis in all the patients, whereas five of them frequent upper respiratory tract infection have been observed as side effect

Conclusions: In this preliminary report, This biosimilar infliximab treatment appears to be safe and effective in paediatric age group on the paediatric patients with non-infectious uveitis. These results must be supported by multicenter studies and registries.

Disclosure of Interest: None declared

DOI: 10.1136/annrheumdis-2018-eular.4895

\section{THU0565 \\ NEEDS ASSESSMENT OF TRAINING IN PAEDIATRIC RHEUMATOLOGY AMONG SPANISH PAEDIATRICIANS. MULTICENTER DESCRIPTIVE STUDY}

C. Udaondo, S. Murias, R. Alcobendas, A. Remesal. Paediatric Rheumatology, University Hospital La Paz, Madrid, Spain

Background: There is a perception that care for paediatric patients with pathology

Rheumatic is heterogeneous, as several previous publications have shown. Likewise, in Spain we do not have the recognition of a specialisation in Rheumatology Paediatric, for which it is possible that the training in this field is not sufficiently specific. This could be detrimental to the best care received on the part of the patients.

Paediatric rheumatology has some specific characteristics that make it unique, but there is yet no recognised specialisation in some countries.

Objectives: To examine the needs assessment for specific training in paediatric rheumatology among paediatricians and paediatricians in training from different countries using a specific questionnaire.
Methods: An online anonymous questionnaire was sent to paediatricians and paediatricians in training from different centres in Spain, London an Mexico. Data on working place, city, and perception of the state of training in paediatric rheumathology in their workplace were collected.

Results: A total of 447 questionnaires were answered: 287 by senior paediatricians $(64.5 \%)$ and 125 by paediatric trainees (28.1\%); $96.4 \%$ in different Spanish cities and $3.6 \%{ }^{16}$ a in other countries.

For $54.7 \%(254)$ of the respondents there is no specialisation in paediatric rheumatology in their workplace. The main responsible of children with rheumatic pathology is a paediatric rheumathologist in $59.7 \%$ (257) cases, with or without recognised specialisation, a general paediatrician in $21.2 \%(91)$ cases and an adult rheumathologist in $19.1 \%(82)$ cases

$96.8 \%$ of the respondents believe that there should be an accredited training in paediatric rheumatology. The formative aspects that were believed to be more important were the knowledge in paediatric rheumatology, general paediatrics and immunology, and the most valued capacities were the physical exploration arthrocentesis and infiltration and the performance of musculoskeletal ultrasound Conclusions: The majority of paediatricians reached believe there is a lack of recognised specialisation in paediatric rheumatohology in Spain, and a need fo accredited training. The attention to children with rheumathic diseases in Spain is heterogeneous. This survey reinforces the perception that training in paediatric rheumatology in our country should be improved.

\section{REFERENCES}

[1] De Inocencio J, Antón J. Reumatologia pediátrica. Breve historia y situación de la especialidad en España. Acta Rheumatologica 2014;1:1.

[2] Spencer $\mathrm{CH}$. Why should pediatric rheumatology be recognized as a separate subspecialty: An open letter to medical councils and government agencies. Pediatr Rheumatol Online J 2007;21:21.

[3] Passo M. Status Report for Pediatric Rheumatology: What Needs to Be Done? Arthritis \& Rheumatism (Arthritis Care \& Research) 2006 December 15;55(6):833-835.

[4] Woodward AL, Harris ZL. Employment of a needs assessment survey to shape a novel web-based pediatric rheumatology curriculum for primary care providers. Pediatric Rheumatology 2013;11:26.

Acknowledgements: Dr. Lacassagne, Dr Khaosut and Dr Sifuentes. Great Ormond Street Hospital, London.

Disclosure of Interest: None declared

DOI: 10.1136/annrheumdis-2018-eular.5185

\section{THU0566 ASSESSMENT OF BEHAVIOURAL DISORDERS IN CHILDREN WITH JUVENILE IDIOPATHIC ARTHRITIS}

D. Dop, C.E. Niculescu. Departement of Pediatrics, University of Medicine and Pharmacy of Craiova, Craiova, Romania

Background: Juvenile Idiopathic Arthritis(JIA) is the most frequent paediatric rheumatologic disease which, because of its chronic, winding evolution, long-term treatment and dreadful complications, has a powerful impact on the somatic and psycho-social development of the children affected by it.

Methods: A number of 49 children with Juvenile Idiopathic Arthritis followed-up in the District Emergency University Hospital in Craiova and aged between 6 and 18 , and a control group consisting in 49 healthy children of similar age and sex, were examined using the Child Behaviour Checklist (CBCL).

Results: Our results showed that $57.1 \%$ of the patients with JIA were classified as borderline and $6.12 \%$ as clinical behaviour, compared to the control group in which just $16.3 \%$ presented Internalising and Externalising problems. Thus, the majority of children with progressing forms of JIA presented social adjustment disorders, anxiety/depression, attention deficit, and 3 of them, males, presented verbal/physical aggressiveness and Rule-Breaking Behaviour. While among the patients with JIA it was mostly the feminine gender that presented behavioural disorders, in the control group all children with Internalising and Externalising problems were males.

Conclusions: Children with JIA must be carefully kept under observation for an early detection and treatment of behavioural deviations. Further studies are nec essary, on large groups of patients, in order to identify the manner in which Juvenile Arthritis affects the patient and his or her family.

Acknowledgements: The authors declare that they have no conflict of interests.

Disclosure of Interest: None declared

DOI: 10.1136/annrheumdis-2018-eular.4223 